\title{
Enhanced Recovery After Surgery (ERAS) protocol in bariatric and metabolic surgery (BMS) - analysis of practices in nutritional aspects from five continents
}

\author{
Carina Rossoni ${ }^{1,6}$ (D) Daniéla Oliveira Magro ${ }^{2}$ (D) $\cdot$ Zélia Coelho Santos $^{3}$ (D) Maria Paula Carlini Cambi ${ }^{4}$ (D) \\ Luciana Patias ${ }^{5}$ (I) $\cdot$ Rossela Bragança $^{3}$ (I) $\cdot$ Douglas Pellizzaro $^{6}$ (i) $\cdot$ Chetan Parmar $^{7}$ (D) $\cdot$ Rui Ribeiro $^{3}$ (i)
}

Received: 17 May 2020 / Revised: 30 June 2020 / Accepted: 2 July 2020

(C) Springer Science+Business Media, LLC, part of Springer Nature 2020

\begin{abstract}
This study aims to understand the prevalent practices on the nutritional aspects of the enhanced recovery after surgery (ERAS) protocol based on the knowledge and practice of surgeons, nutritionists, and anesthesiologists who work in the bariatric and metabolic surgery (BMS) units worldwide. This cross-sectional study enrolled BMS unit professionals from five continentsAfrica, America, Asia, Europe, and Oceania. An electronic questionnaire developed by the researchers was provided to evaluate practices about the three nutritional aspects of ERAS protocol in BMS (Thorel et al. 2016): preoperative fasting, carbohydrate loading, and early postoperative nutrition. Only surgeons, nutritionists, and anesthesiologists were invited to participate. One hundred twenty-five professionals answered the questionnaires: 50.4\% from America and 39.2\% from Europe. The profile of participating professionals was bariatric surgeons $70.2 \%$, nutritionists $26.4 \%$, and anesthesiologists $3.3 \%$. Approximately $47.9 \%$ of professionals work in private services, for about 11 to 20 years (48.7\%). In all continents, a large majority were aware of the protocol. Professionals from the African continent reported having implemented the ERAS bariatric protocol $4.0 \pm 0$ years ago. It is worth mentioning that professionals from the five continents implemented the ERAS protocol based on the published literature $(p=0.012)$. About preoperative fasting abbreviation protocol, a significant difference was found between continents and consequently between services $(p=0.000)$. There is no uniformity in the conduct of shortening of fasting in the preoperative period and the immediate postoperative period. Early postoperative (PO) period protein supplementation is not performed in a standard fashion in all units globally. ERAS principles and practices are partial and insufficiently implemented on the five continents despite the prevalent knowledge of professionals based on evidence. Moreover, there is no uniformity in fasting, immediate postoperative diet, and early protein supplementation practices globally.
\end{abstract}

Carina Rossoni

rossonicarina@gmail.com

Daniéla Oliveira Magro

danimagro@terra.com.br

Zélia Coelho Santos

zelia.coelho.santos@gmail.com

Maria Paula Carlini Cambi

mpcarlini@hotmail.com

Luciana Patias

lu_patias@yahoo.com.br

Rossela Bragança

rosselab@gmail.com

Douglas Pellizzaro

douglas.pellizzaro@unoesc.edu.br

Chetan Parmar

cparmar@nhs.net
Rui Ribeiro

ruijsribeiro@gmail.com

1 Postgraduate in Biosciences and Health of University of the West of Santa Catarina-Unoesc, Street Getúlio Vargas, 2195, Flor da Serra Neighborhood, Joaçaba, Brazil

2 Departament of Surgery of Faculty of Medical Sciences at Campinas State University-Unicamp, Campinas, Brazil

3 Multidisciplinary Center for Metabolic Disease at Clínica of Santo António - Lusíadas, Amadora, Portugal

4 Dr Giorgio Baretta Clinic, Curitiba, Paraná, Brazil

5 Dr. Glauco Alvarez Clinic, Santa Maria, Brazil

6 Undergraduate Medical Course of University of the West of Santa Catarina-Unoesc, Joaçaba, Brazil

7 University College Hospital, Whittington Health NHS Trust, London, England 


\section{Introduction}

Enhanced recovery after surgery (ERAS) protocol is a program for patients' safe and faster postoperative recovery supported by evidence-based recommendations, such as randomized clinical studies, systematic reviews, and meta-analyzes $[1,2]$. Implementation of ERAS protocol allows a better assistance in pre and postoperative journey of patients and ensures less postoperative morbidity, quicker recovery, and reduced length of hospital stay (LOS) [3-6].

The first studies were conducted by Professor Henrik Kehlet, in the 1990s, which brought a great impact on perioperative care, proposing changes considered radical when compared with traditional care practiced at that moment. In the International literature, it became known as "fast-track surgery," translated as a protocol for accelerated postoperative recovery [3].

The ERAS protocol started with colorectal subspecialty [1] in an active and multimodal approach for the care of surgical patients, resulting in optimized outcomes in terms of reduced morbidity, faster recovery, and shorter LOS in reference units [7-12].

In bariatric and metabolic surgery (BMS), ERAS protocol was introduced recently, and recommendations were published 4 years ago [13]. The bariatric protocol contains 21 components, distributed in the three steps: pre, intra and postoperative periods. Among these, there are components in the nutritional field, which directly and indirectly contribute to the accelerated recovery of the morbidly obese, by abbreviation of fasting through carbohydrate supplementation in the preoperative period in addition to the introduction of diet and protein supplementation, vitamins, and minerals in the immediate postoperative period [13].

These recommendations have been introduced slowly and insufficiently in reference units for bariatric surgery. The Units that adopted this protocol have not produced convincing literature, despite the high level of evidence already demonstrated. This aspect can be considered a deficit in modern surgical practice [13].

In this context, this study aims to evaluate the knowledge and understanding of surgeons, nutritionists, and anesthesiologists of the nutritional aspects of ERAS protocol.

\section{Methods}

\section{Study Design and Population}

This cross-sectional study invited 125 BMS professionals from all five continents - Africa, America, Asia, Europe, and Oceania. The survey was shared via social media. The participation was voluntary. Only surgeons, nutritionists, and anesthesiologists working in a BMS unit were included.

\section{Assessment Tool}

An electronic questionnaire developed by the researchers (Table 1) was shared to evaluate the practice of the three nutritional aspects of the ERAS protocol in bariatric and metabolic surgery [13]:

- Preoperative fasting: Obese patients may take clear fluids up to $2 \mathrm{~h}$ and solids up to $6 \mathrm{~h}$ prior to induction of anesthesia. Further data are necessary in diabetic patients with autonomic neuropathy, due to potential risk of aspiration of carbohydrate loading and after early postoperative nutrition (recommendation grade — strong).

- Carbohydrate loading: While preoperative oral carbohydrate conditioning in patients undergoing major abdominal elective surgery has been associated with metabolic and clinical benefits, further data are required in morbidly obese patients. Similarly, further data are needed on preoperative carbohydrate conditioning in patients with gastroesophageal reflux who may be at increased risk of aspiration during anesthetic induction (recommendation grade - strong).

- Early postoperative nutrition: Protein intake should be monitored. Iron, vitamin B12, and calcium supplementation is mandatory (recommendation grade - strong).

\section{Statistical Analysis}

For quantitative variables with normal distribution, mean \pm standard deviation (SD) was used. The qualitative variables were shown as percentages, and the chi-square test was used to compare the proportions among groups (of independent samples). The exact Fisher test was used when the total number of cases was lower than 5 . The data were analyzed using IBM SPSS Statistics for Windows, version 24.0 (IBM Corporation, Armonk, NY, USA). The significance level adopted was 5\% $(P$ value $<0.05)$.

\section{Results}

One hundred twenty-five professionals responded to the sent questionnaires, $50.4 \%$ from American continent and 
Table 1 The questionnaire sent for the study

1. What is your country?

2. What is your professional background?

( ) Surgeon

( ) Anesthesiologist

( ) Nutritionist

( ) Other

3. Which bariatric surgery unit, do you work in?

4.Do you work in a:

( ) Public service

( ) Private service

( ) Both

5. How long have you worked with bariatric surgery?

( ) 1 to 5 years

( ) 6 to 10 years

( ) 11 to 20 years

( ) $\geq 20$ years

6. Do you know ERAs protocol for bariatric surgery?

( ) No

( ) Yes

7. Do you follow ERASs protocol at your workplace? No, mention two reasons:

8. Do you follow ERASs protocol at your workplace? How long has it been implemented?

$\begin{array}{ll}\text { ( ) } 1 \text { year } & \text { ( ) } 6 \text { years } \\ \text { ( ) } 2 \text { years } & \text { ( ) } 7 \text { years } \\ \text { ( ) } 3 \text { years } & \text { ( ) } 8 \text { years } \\ \text { ( ) } 4 \text { years } & \text { ( ) } 9 \text { years } \\ \text { ( ) } 5 \text { years } & \text { ( ) } \geq 10 \text { years }\end{array}$

9. If you answered "yes" to the latter question, which ERAs protocol do you follow?

( ) Solid diet $(8 \mathrm{~h})+$ oral protein supplement $400 \mathrm{ml}(6 \mathrm{~h})+200 \mathrm{ml}(2 \mathrm{~h})$

( ) Solid diet $(8 \mathrm{~h})+$ oral maltodextrin supplement only (12\%), $400 \mathrm{ml}$ (6 h) e $200 \mathrm{ml}(2 \mathrm{~h})$

( ) Solid diet ( $8 \mathrm{~h})+$ sweet tea (12 g sugar), $400 \mathrm{ml}(6 \mathrm{~h})$ e $200 \mathrm{ml}(2 \mathrm{~h})$

( ) Solid diet $(6 \mathrm{~h})+$ oral protein supplement $400 \mathrm{ml}(4 \mathrm{~h})+200 \mathrm{ml}(2 \mathrm{~h})$

( ) Solid diet $(6 \mathrm{~h})+$ oral maltodextrin supplement only (12\%), $400 \mathrm{ml}$ (4 h) e $200 \mathrm{ml}(2 \mathrm{~h})$

( ) Solid diet (6 h) + sweet tea (12 g sugar), $400 \mathrm{ml}$ (4 h) e $200 \mathrm{ml}(2 \mathrm{~h})$

( ) Oral maltodextrin supplement only (12\%) $200 \mathrm{ml}(2 \mathrm{~h})$

( ) Sweet tea (12 g sugar) $200 \mathrm{ml}(2 \mathrm{~h})$

10. Other ERAs protocol do you follow?

11. Your protocol choice was based on:

( ) Literature data

( ) Your own results

12. If you are an anesthesiologist, answer what of the following solutions do you use for intraoperative volume replacement?

( ) Plasmalyte

( ) Ringer lactate

( ) Saline solution- $\mathrm{NaCl} 0.9 \%$

( ) Other

( ) Not applicable
Table 1 (continued)

13. If you are an anesthesiologist, answer what intraoperative volume replacement strategy do you use?

( ) Restrictive

( ) Goal-directed hemodynamic

( ) Liberal

( ) Other

( ) Not applicable

14. What protocol do you follow after surgery?

postoperative oral hydration after anesthesiologic recovery period

( ) Liquid diet (soup, juice, milk...) $4 \mathrm{~h}$ postoperative

( ) Liquid diet (soup, juice, milk...) $6 \mathrm{~h}$ postoperative

( ) Liquid diet (soup, juice, milk...) $12 \mathrm{~h}$ postoperative

( ) Liquid diet (soup, juice, milk...) $24 \mathrm{~h}$ postoperative

15. What protocol oral protein supplement do you follow after surgery?

( ) $4 \mathrm{~h}$ postoperative

( ) $6 \mathrm{~h}$ postoperative

( ) $8 \mathrm{~h}$ postoperative

( ) $12 \mathrm{~h}$ postoperative

( ) $24 \mathrm{~h}$ postoperative

( ) Other

$39.2 \%$ from the European continent, largely represented by Brazil (41.6\%) and Portugal (23.2\%) from the two continents, respectively (Fig. 1).

As for the profile of professionals who participated in this study, $70.2 \%$ were bariatric surgeons, $26.4 \%$ were nutritionists, and $3.3 \%$ were anesthesiologists. There were no differences in relation to the type of service the respondents worked (private or public) and duration of time the professionals were working in the area of BMS. Approximately $47.9 \%$ of professionals work in private service, for about 11 to 20 years (48.7\%) (Table 2)

Table 3 describes the professionals' ERAS protocol knowledge, its use, time elapsed since implementation, and whether it was based on available literature or on individual unique results. On all continents, a large majority were aware of the protocol. Interestingly $11(8,3 \%)$ respondents were still not aware of ERAS protocol. The professionals from the African continent reported having implemented the ERAS bariatric protocol for longest duration ( $4.0 \pm 0$ years). All professionals from the five continents, who implemented the ERAS protocol, based it on the published literature rather than personal experience $(P=0.012)$.

When analyzing the preoperative fasting abbreviation protocol, an important difference was found between continents and consequently between services $(P=0.000)$. This information is described in Table 4.

There is no uniformity in the practice aiming to reduce fasting in the preoperative period (Fig. 2). On the African continent, the patients take the last solid diet $8 \mathrm{~h}$ before surgery. Sweetened tea (ST) with sugar is offered $6 \mathrm{~h}(400 \mathrm{ml})$ and $2 \mathrm{~h}(200 \mathrm{ml})$ before surgery or just oral protein supplementation (OPS) $2 \mathrm{~h}(200 \mathrm{ml})$ before; in America, the last solid diet $8 \mathrm{~h}$ and oral supplementation with only maltodextrin 


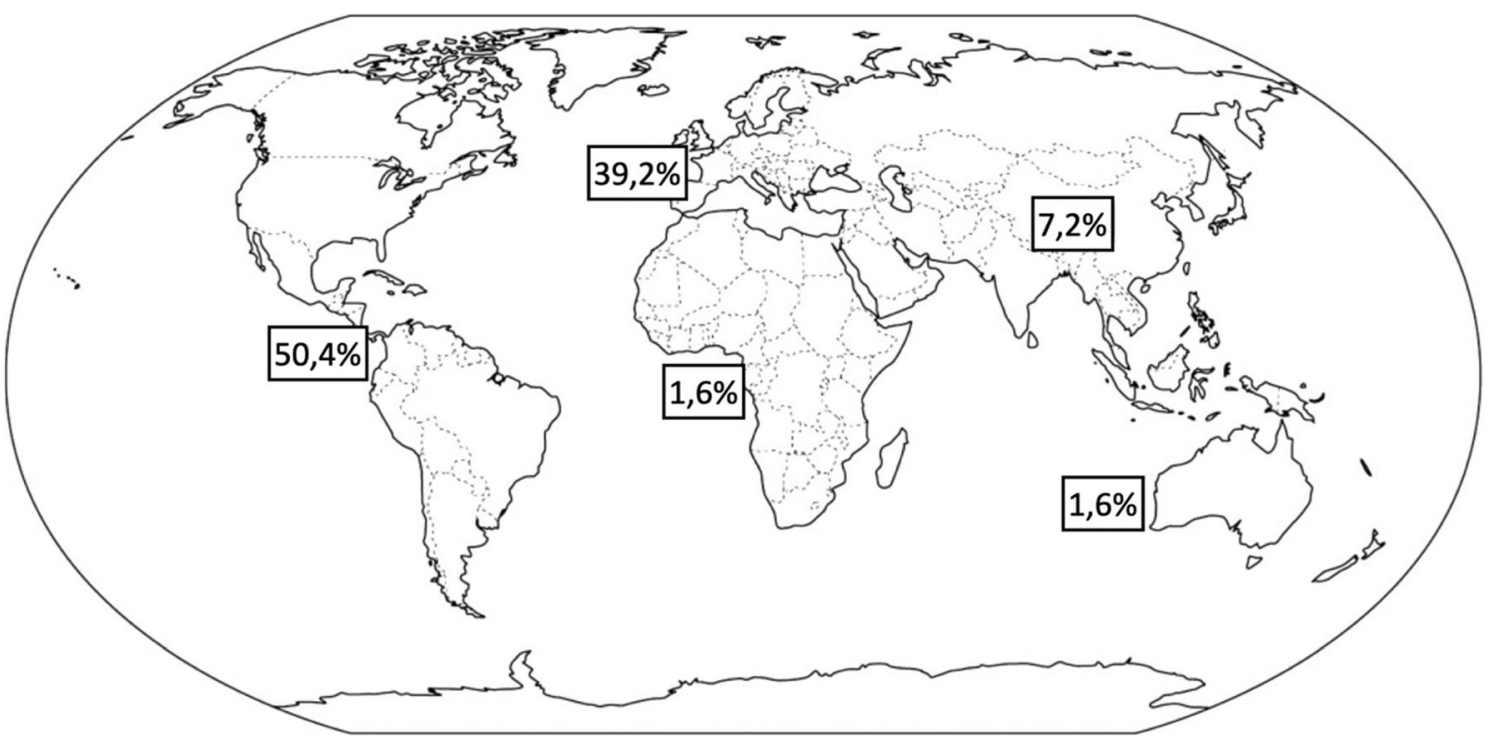

Fig. 1 Distribution of study participants according to the continent, who work around bariatric and metabolic surgery

(OMSO) prevailed $6 \mathrm{~h}(400 \mathrm{ml})$ and $2 \mathrm{~h}(200 \mathrm{ml})$ before surgery; in Asia there was no prevalent protocol; in Europe, ST (12 g) prevailed $2 \mathrm{~h}(200 \mathrm{ml})$; and in Oceania, the last solid diet $8 \mathrm{~h}$ and OPS only $6 \mathrm{~h}(400 \mathrm{ml})$ and $2 \mathrm{~h}(200 \mathrm{ml})$ before surgery.

As for the nutritional protocol in the immediate postoperative period, there was no uniformity or prevalent practice in the continents, as shown in the results in Table 5.

Early postoperative period protein supplementation is not performed in a standard fashion in all the Units in the five continents. Majority respondents from America and Europe mentioned that the protein supplement was introduced within the first $24 \mathrm{~h}$ after surgery rather than $12 \mathrm{~h}$ after surgery (Table 6).

Nutritional protocols practiced in the five continents, through the abbreviation of the preoperative fasting and the introduction of the liquid diet and early protein supplementation in the postoperative period, are shown in Fig. 3.

\section{Discussion}

To our knowledge, this is the first intercontinental and interdisciplinary study aiming to evaluate nutritional aspects of ERAS protocol through survey asked to BMS unit professionals worldwide.

The number of bariatric surgeries has increased significantly worldwide. According to Angrisani et al. [14], between 2008 and 2016, there has been an increase from 344,221 to 685,874 BMS interventions. The first-choice procedures were, in order of magnitude, sleeve gastrectomy (SG), Roux-en-Y gastric bypass (RYGB), and one anastomosis gastric bypass (OAGB).
Table 2 Characterization of professionals from five continents, who work in bariatric and metabolic surgery services

\begin{tabular}{|c|c|c|c|c|c|}
\hline & $\begin{array}{l}\text { Total } n=125 \\
(100.0)\end{array}$ & $\begin{array}{l}\text { Surgery } n=85 \\
(70.2)\end{array}$ & $\begin{array}{l}\text { Nutritionist } \\
n=32(26.4)\end{array}$ & $\begin{array}{l}\text { Anesthesiologist } \\
n=4(3.3)\end{array}$ & $\begin{array}{l}P \\
\text { value }\end{array}$ \\
\hline \multicolumn{6}{|c|}{ Unit surgery bariatric work } \\
\hline $\begin{array}{l}\text { Private and } \\
\text { public service }\end{array}$ & $38(31.4)$ & $30(35,2)$ & $6(18.7)$ & $2(50.0)$ & \\
\hline Private service & $58(47.9)$ & $37(43,5)$ & $20(62.6)$ & $1(25.0)$ & \\
\hline Public service & $25(20.7)$ & $18(21,1)$ & $6(18.7)$ & $1(25.0)$ & 0.242 \\
\hline \multicolumn{6}{|c|}{ How long have you worked surgery bariatric } \\
\hline 1 the 5 years & $12(9.9)$ & $8(9,4)$ & $2(6,3)$ & $2(50.0)$ & \\
\hline 6 the 10 years & $23(19.0)$ & $18(21,2)$ & $5(15,6)$ & 0 & \\
\hline 11 the 20 years & $59(48.7)$ & $39(45.9)$ & $19(59,3)$ & $1(25.0)$ & 0.230 \\
\hline$\geq 20$ years & $26(21.5)$ & $20(23,5)$ & $5(15,6)$ & $1(25.0)$ & \\
\hline No available data & $1(0.9)$ & - & $1(3.2)$ & - & \\
\hline
\end{tabular}

Values are presented as number (\%) 
Table 3 Association of the professional's knowledge, the implementation, and the period of the ERAS protocol in the bariatric and metabolic surgery service in the five continents

\begin{tabular}{|c|c|c|c|c|c|c|}
\hline & Africa $n=2(1.6)$ & America $n=62(51.2)$ & Asia $n=9(7.4)$ & Europe $n=49$ (40.4) & Oceania $n=02(1.6)$ & $P$ value \\
\hline \multicolumn{7}{|c|}{ Know ERAS protocol SB } \\
\hline Yes & $2(100.0)$ & $55(88.7)$ & $8(88.9)$ & $46(93.8)$ & $2(100.0)$ & 0.672 \\
\hline No & 0 & $7(11.3)$ & $1(11.1)$ & $3(6.2)$ & 0 & \\
\hline \multicolumn{7}{|c|}{ Do you follow ERAS protocol at your workplace } \\
\hline Yes & $2(100)$ & $29(46.7)$ & $7(77.7)$ & $28(57.1)$ & $2(100.0)$ & 0.513 \\
\hline No & 0 & $25(40.3)$ & $1(11.1)$ & $19(38.7)$ & 0 & \\
\hline Partially & 0 & $4(6.4)$ & 0 & $2(4.2)$ & 0 & \\
\hline Sem informação & - & $4(6.4)$ & $1(11.1)$ & - & - & \\
\hline \multicolumn{7}{|c|}{ How long ERAS it been implemented } \\
\hline (Years) & $4.0 \pm 0.0$ & $2.85 \pm 0.95$ & $2.44 \pm 0.88$ & $2.78 \pm 0.77$ & $2.44 \pm 1.41$ & 0.23 \\
\hline \multicolumn{7}{|c|}{ Your protocol choice was based on: } \\
\hline Literature data & 0 & $37(59.7)$ & $6(66.7)$ & $15(30.6)$ & $1(50.0)$ & \\
\hline Your own results & $2(100.0)$ & $13(20.9)$ & $1(11.1)$ & $17(34.7)$ & $1(50.0)$ & $0.012 *$ \\
\hline Sem informação & - & $12(19.4)$ & $2(22.2)$ & $17(34.7)$ & - & \\
\hline
\end{tabular}

Values are presented as mean $\pm \mathrm{SD}$ or number $(\%), P<0.005^{*}$

BMS is the most effective treatment for morbid obesity sustaining long-term weight loss and improvement in comorbidities $[15,16]$. Although bariatric surgery was introduced in the 1950 s, it was minimally invasive procedures such as laparoscopy introduced in the 1990s, which made bariatric surgery more acceptable by significantly improving safety and results, which further increased its popularity $[17,18]$. This growing demand has stimulated permanent technical evolution, which in turn has optimized assistance and made its results sustainable. However, since it is an expensive treatment and not covered by insurance in many countries, the need to contain health costs has somewhat limited its expansion, and only a small percentage of patients can enjoy its benefits [19]. In the national registry of International Federation for the Surgery of Obesity and Metabolic Disorders (IFSO), only about $0.01 \%$ of the world population was taking advantage of bariatric surgery [20]. The safety of BMS has further helped in its growing popularity. ERAS protocol has significantly helped in the same. Since first published ERAS protocols for BMS in 2016 [13], the protocols for accelerated recovery have been gradually implemented in BMS centers around the world, seeking to continuously improve the teams' performance in the face of the peculiar challenges that the bariatric patients raise $[18,21]$.

Table 4 Abbreviation protocol for preoperative fasting in bariatric and metabolic surgery services according to each continent

\begin{tabular}{|c|c|c|c|c|c|c|}
\hline & $\begin{array}{l}\text { Africa } \\
(n=2)\end{array}$ & $\begin{array}{l}\text { America } \\
(n=30)\end{array}$ & $\begin{array}{l}\text { Asia } \\
(n=6)\end{array}$ & $\begin{array}{l}\text { Europe } \\
(n=27)\end{array}$ & $\begin{array}{l}\text { Oceania } \\
(n=2)\end{array}$ & $P$ value \\
\hline \multicolumn{7}{|l|}{ Solid diet $(8 \mathrm{~h})$} \\
\hline+ OMSO $12 \%+400 \mathrm{ml}(6 \mathrm{~h})+200 \mathrm{ml}(2 \mathrm{~h})$ & 0 & $10(33.3)$ & 0 & $2(7.4)$ & 0 & $0.000^{*}$ \\
\hline +OPS $400 \mathrm{ml}(6 \mathrm{~h})+200 \mathrm{ml}(2 \mathrm{~h})$ & 0 & $9(30.0)$ & $2(33.3)$ & $3(11.1)$ & $1(50.0)$ & \\
\hline$+\mathrm{ST}(12 \mathrm{~g}) 400 \mathrm{ml}(6 \mathrm{~h})+200 \mathrm{ml}(2 \mathrm{~h})$ & $1(50)$ & 0 & $1(16.6)$ & $3(11.1)$ & 0 & \\
\hline Oral protein supplement $200 \mathrm{ml}(2 \mathrm{~h})$ & $1(50)$ & $4(13.4)$ & $2(33.3)$ & $2(7.4)$ & 0 & \\
\hline \multicolumn{7}{|l|}{ Solid diet $(6 \mathrm{~h})$} \\
\hline +OPS $400 \mathrm{ml}(4 \mathrm{~h})+200 \mathrm{ml}(2 \mathrm{~h})$ & 0 & 0 & $1(16.6)$ & $2(7.4)$ & 0 & \\
\hline +ST(12 g) $400 \mathrm{ml}(4 \mathrm{~h})+200 \mathrm{ml}(2 \mathrm{~h})$ & 0 & 0 & 0 & $3(11.1)$ & 0 & \\
\hline Oral maltodextrin supplement only $12 \%$ & 0 & $4(13.4)$ & 0 & 0 & 0 & \\
\hline Sweet tea $12 \mathrm{~g}$ & 0 & $1(3.3)$ & 0 & $10(37.0)$ & 0 & \\
\hline Other & 0 & $2(6.6)$ & 0 & $2(7.4)$ & $1(50.0)$ & \\
\hline
\end{tabular}

Values are presented as number $(\%) P<0.001 *$. OMSO, oral maltodextrin supplement only [12]; OPS, oral protein supplement; ST, sweet tea (12 g sugar) 


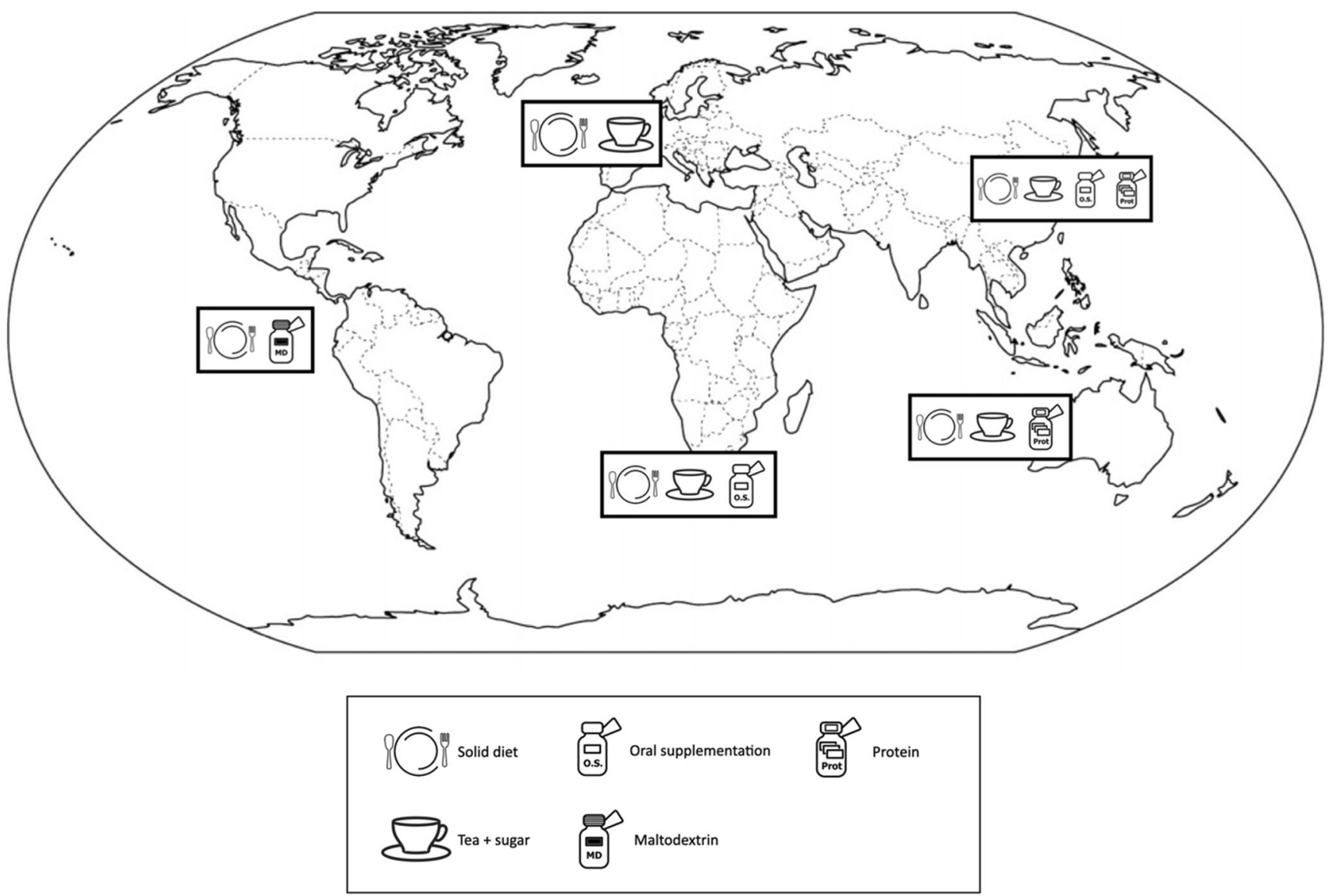

Fig. 2 Abbreviation protocol for preoperative fasting in bariatric and metabolic surgery units according to each continent

In our study, there were no differences between public and private services regarding the time of implementation of the ERAS protocol globally. Surgeons, nutritionists, and anesthesiologists from private BMS centers have been working in the area for over 11 years and report having knowledge about ERAS. When they implemented changes, it was based on data from the literature. The obstacles to the implementation of the ERAS principles and mechanisms that allow the accelerated recovery of the bariatric patient are usually related to the level of prior education and advice provided to the patient, the resistance to the implementation of pre and post-operative nutritional care, of ambulation, and abandoning the use of narcotic analgesia. Another factor is the relative lack of robust prospective studies on the effectiveness of ERAS in BMS, especially regarding nutritional aspects related to the reduction of morbidity, mortality, and the length of stay (LOS) [21, 22].

To avoid complications after BMS, such as infections, poor healing, gastrointestinal disorders, fatigue, or reduced functional capacity, nutritional intervention is strongly recommended [23]. Healthy nutrition also improves the immunity of the individual. Regarding the LOS, Dogan et al. [24] and Bevilacqua et al. [23] obtained a reduction in the mean

Table 5 Immediate postoperative nutritional protocol in bariatric and metabolic surgery services according to the five continents

\begin{tabular}{llllll}
\hline & $\begin{array}{l}\text { Africa } \\
(n=02)\end{array}$ & $\begin{array}{l}\text { America } \\
(n=54)\end{array}$ & $\begin{array}{l}\text { Asia } \\
(n=08)\end{array}$ & $\begin{array}{l}\text { Europe } \\
(n=43)\end{array}$ & $\begin{array}{l}\text { Oceania } \\
(n=02)\end{array}$ \\
\hline $\begin{array}{l}\text { Oral hydration in post-anesthesia recovery } \\
\text { Liquid diet (soup, juice, milk...) }\end{array}$ & 0 & $11(20.4)$ & $3(37.5)$ & $8(18.6)$ & 0 \\
$4 \mathrm{~h}$ & 0 & $2(3.8)$ & $1(12.5)$ & $2(4,6)$ & 0 \\
$6 \mathrm{~h}$ & $1(50.0)$ & $11(20.4)$ & 0 & $10(23.3)$ & 0 \\
$12 \mathrm{~h}$ & 0 & $13(24.0)$ & $3(37.5)$ & $7(16.2)$ & $1(50.0)$ \\
$24 \mathrm{~h}$ & $1(50.0)$ & $17(31.4)$ & $1(12.5)$ & $16(37.2)$ & $1(50.0)$ \\
\hline
\end{tabular}

Values are presented as number $(\%)$ 
Table 6 Nutritional protocol for protein supplementation in the postoperative period, in bariatric and metabolic surgery units across the five continents

\begin{tabular}{llllll}
$\begin{array}{l}\text { Africa } \\
(n=02)\end{array}$ & $\begin{array}{l}\text { America } \\
(n=57)\end{array}$ & $\begin{array}{l}\text { Asia } \\
(n=08)\end{array}$ & $\begin{array}{l}\text { Europe } \\
(n=43)\end{array}$ & $\begin{array}{l}\text { Oceania } \\
(n=02)\end{array}$ & $P$ value \\
\hline
\end{tabular}

Protein supplementation

$\begin{array}{rllllll}4 \mathrm{~h} & 0 & 1(1.7) & 0 & 0 & 0 & 0.605 \\ 6 \mathrm{~h} & 0 & 4(7.0) & 0 & 1(2.3) & 0 & \\ 8 \mathrm{~h} & 0 & 2(3.5) & 0 & 3(6.9) & 0 & \\ 12 \mathrm{~h} & 2(50.0) & 7(12.2) & 2(25.0) & 4(9.3) & 1(50.0) & \\ 24 \mathrm{~h} & 0 & 24(42.1) & 2(25.0) & 14(32.5) & 0 \\ \text { Other } & 2(50.0) & 18(31.5) & 4(50.0) & 21(48.8) & 1(50.0)\end{array}$

Values are presented as number $(\%)$

hospital stay in patients undergoing laparoscopic primary RYGB, with no difference in the rates of complications, after the implementation of the "fast track" program, which included the abbreviation of preoperative fasting and early postoperative diet.
The shortening of preoperative fasting duration is strongly recommended in the ERAS protocol for BMS [13]. In a recent prospective study in India, two groups of patients who underwent laparoscopic SG were compared, one with an ERAS protocol with a $600-880 \mathrm{Kcal} /$ day low-calorie diet in the week prior to the operation, ingestion of sugary liquids $2-3 \mathrm{~h}$ before surgery, and resumption of fluid intake $2-3 \mathrm{~h}$ after surgery, another with a standard protocol. In the "standard protocol," an absolute fast was performed since the previous night, and the resumption of intake occurred only $12 \mathrm{~h}$ postoperatively. Differences in favor of the ERAS protocol were observed in the time of the beginning of early ambulation, in the reduction of postoperative pain in the use of resource analgesia and the LOS [25].

It should be noted that in morbidly obese and diabetic patients with dysautonomic neuropathy, additional data should be evaluated by the team, due to a potential risk of aspiration at the time of anesthesia. Before anesthetic induction, the last meal should consist of a solid diet $6 \mathrm{~h}$ before and clear fluids
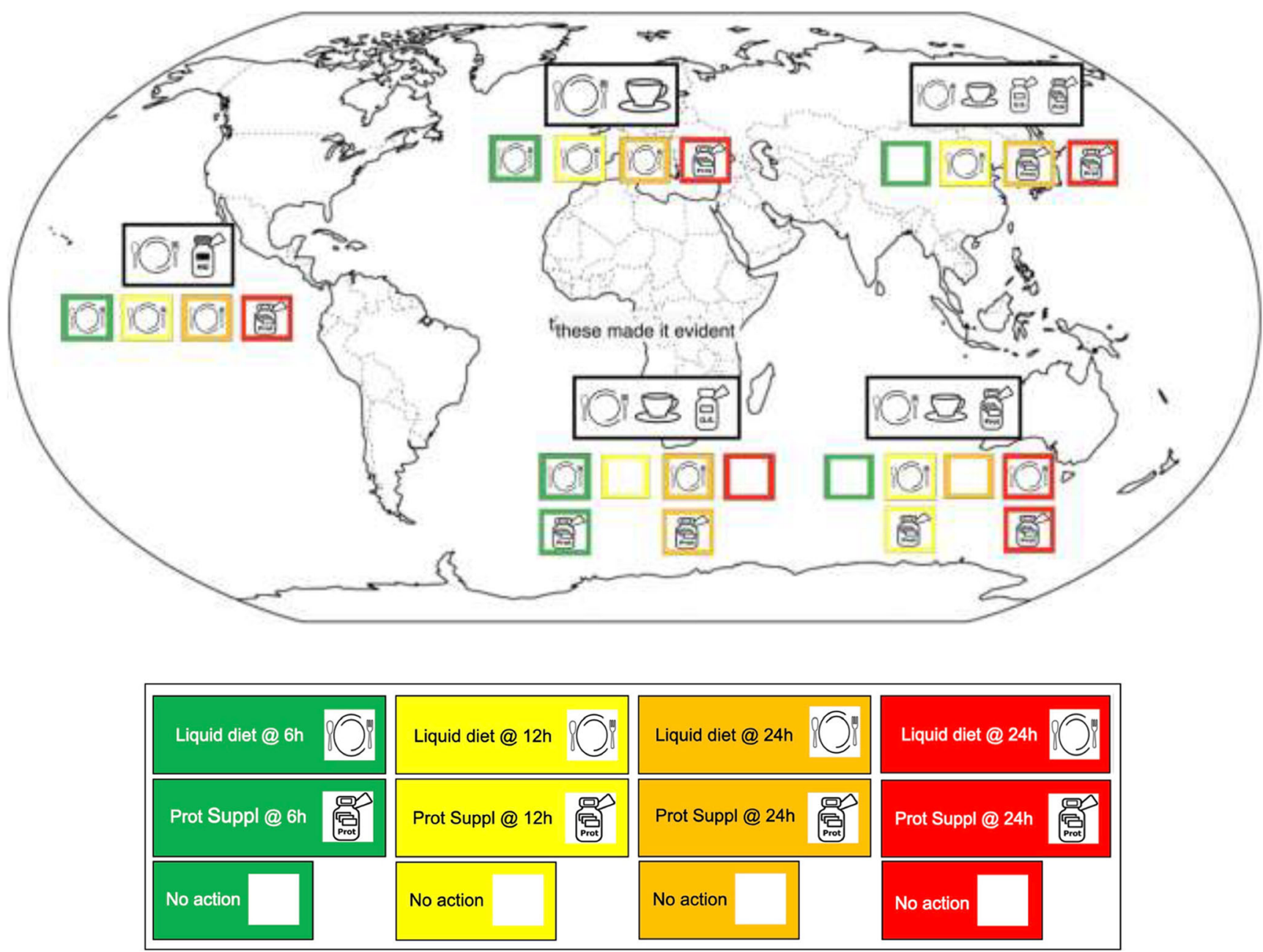

Fig. 3 Abbreviation protocol for preoperative fasting, liquid oral diet, and postoperative nutritional protein supplementation of participant units, according to the continent where they work in bariatric and metabolic surgery unit 
$2 \mathrm{~h}$ before surgery. When analyzing this recommendation, in our study, we observed a difference between the continents and consequently between the bariatric and metabolic surgery centers, with no uniformity between the responses.

The nutritional composition of the clear liquids recommended in the abbreviation of fasting is based on carbohydrates, which are directly associated with metabolic and clinical benefits, such as the attenuation of insulin resistance and the reduction of nitrogen and protein losses, keeping the fat free mass in the postoperative period [26]. In addition to these benefits, Awad et al. [27] and Smith et al. [28] demonstrated that the use of clear fluids with carbohydrates is associated with a significant reduction in the LOS in patients undergoing major abdominal surgery. A review by dietician should be done before discharge to have a planned diet progression in the immediate postoperative period. The balanced meal plan would help in optimal fiber consumption, colonic function, and phytochemical intake.

Another study carried out with diabetic patients found no difference in gastric emptying times when compared with non-diabetic individuals, reinforcing the recommendation through the safety of this practice in BMS [29].

With the same degree of recommendation, postoperative nutrition should be immediate through the introduction of the liquid diet after anesthetic recovery in the first $24 \mathrm{~h}$ when patient is able. The administration of protein supplementation and chewable vitamins and minerals, with emphasis on Vitamin B12, Iron, and calcium is suggested [13]. In this section of questionnaire, similar to the preoperative period, there was no uniformity in the responses regarding the early introduction of the diet and protein supplementation in the postoperative period after BMS. Most continents introduce them between 12 and $24 \mathrm{~h}$ after the operation.

In recent years, there has been a growing interest in the ERAS protocol applied to BMS, although there is a need of raising awareness, implementation, and standardization of the protocol, with a multimodal, simple, efficient, and cost-effective approach in the care of bariatric patients [30]. Aktimur et al. [31] showed significant reduction in the LOS of bariatric surgery patients. It also showed decrease in 30 day postoperative re-hospital visits in ERAS patients compared with standard protocol.

According to Ahmed et al. [32], bariatric surgery involves a complex cohort of patients, who need care based on highquality evidence. Thus, consensus guidelines on the viability of ERAS and real clinical applicability are necessary in order to improve peri- and postoperative results.

As noted in our study, there is no uniformity in the implementation of the nutritional aspects of the ERAS protocol globally. The professionals have scientific knowledge of the protocol; however, they adapt according to the particularities of each center. Despite the small sample, Australia was the only continent which demonstrated consistency in line with ERAS proposals, considering pre and postoperative diet, and supplementation. However, in Australia the predominant techniques were and continue to be the restrictive ones, namely, the gastric band until only a few years ago. With these techniques, it is easier for surgeons to allow the early diet and intake of proteins and supplements as there is no bowel anastomosis to be concerned about. In case of gastric bypass and biliopancreatic techniques, there is a risk of anastomosis [33].

The multidisciplinary optimization of the patient is essential, as well as the multidisciplinary team monitoring in the immediate and late postoperative period. More data focusing on the ERAS parameters from around the world is required $[21,34,35]$.

Our study has several limitations. There were limited responses from around the world. There was unequal distribution of respondents: the highest percentage of responses came from surgeons. There might be a knowledge gap in the surgeons' understanding of the postoperative phase compared with the dieticians. Survey answers are prone for recall bias. We cannot correlate the outcomes of the individual BMS Units based on the responses. There might be differences in the implementation of ERAS in primary and revisional cases. Similarly, the ERAS protocol implementation would vary between the difference in primary bariatric surgeries (e.g., with and without bowel anastomosis). These aspects were not covered in our survey.

\section{Conclusion}

It is established that ERAS protocol is safe, feasible, and efficient in BMS. However, the principles of ERAS are partially and insufficiently implemented around the five continents, despite the published guidelines. Moreover, there is no uniformity in preoperative fasting, immediate postoperative diet, and early protein supplementation team protocols. The effectiveness of the ERAS protocol in other surgical areas is evident; however, studies with outcomes around BMS are limited. Particularly studies looking at the nutritional aspects are missing. We would recommend the IFSO to raise awareness, stringent implementation, and monitoring of ERAS protocol among its members globally.

\section{Compliance with Ethical Standards}

Conflict of Interest The authors declare that they have no conflict of interest.

Ethical Considerations This study was approved by the research ethics committee of the University of Santa Catarina, Brazil ( $\left.{ }^{\circ} 2.032 .578 / 2017\right)$. 


\section{References}

1. Fearon KC, Ljungqvist O, Von Meyenfeldt M, et al. Enhanced recovery after surgery: a consensus review of clinical care for patients undergoing colonic resection. Clin Nutr. 2005;24:466-77.

2. Enhanced Recovery After Surgery - ERAS. History. Disponible: https://ERASsociety.org/about/history/. Acess: 10 april, 2019.

3. Kehlet H. Multimodal approach to control postoperative pathophysiology and rehabilitation. Br J Anaesth. 1997;78(5):606-17.

4. Varadhan KK, Neal KR, Dejong $\mathrm{CH}$, et al. The enhanced recovery after surgery (ERAS) pathway for patients undergoing major elective open colorectal surgery: a meta-analysis of randomized controlled trials. Clin Nutr. 2010;29(4):434-40.

5. Arsalani-Zadeh R, ElFadl D, Yassin N, et al. Evidence-based review of enhancing postoperative recovery after breast surgery. Br J Surg. 2011;98(2):181-96.

6. Singh PM, Panwar R, Borle A, et al. Efficiency and safety effects of applying ERAS protocols to bariatric surgery: a systematic review with meta-analysis and trial sequential analysis of evidence. Obes Surg. 2017:1-13.

7. Basse L, Hjort Jakobsen D, Billesbolle P, et al. A clinical pathway to accelerate recovery after colonic resection. Ann Surg. 2000;232: 51-7.

8. Basse L, Raskov HH, Hjort Jakobsen D, et al. Accelerated postoperative recovery programme after colonic resection improves physical performance, pulmonary function and body composition. Br J Surg. 2002;89:446-53.

9. Wind J, Hofland J, Preckel B, et al. Perioperative strategy in colonic surgery; LAparoscopy and/or FAst track multimodal management versus standard care (LAFA trial). BMC Surg. 2006;6:16.

10. Khoo CK, Vickery CJ, Forsyth N, et al. A prospective randomized controlled trial of multimodal perioperative management protocol in patients undergoing elective colorectal resection for cancer. Ann Surg. 2007;245:867-72.

11. Serclova Z, Dytrych P, Marvan J, et al. Fast-track in open intestinal surgery: prospective randomized study (Clinical Trials Gov Identifier no. NCT00123456). Clin Nutr. 2009;28:618-24.

12. Muller S, Zalunardo MP, Hubner M, et al. A fast-track program reduces complications and length of hospital stay after open colonic surgery. Gastroenterology. 2009;136:842-7.

13. Thorell A, MacCormick AD, Awad S, et al. Guidelines for perioperative care in bariatric surgery: enhanced recovery after surgery (ERAS) society recommendations. World J Surg. 2016;40:206583 .

14. Angrisani L, Santonicola A, Lovino P, et al. Primary, endoluminal, and revisional procedures. Obes Surg. 2016;2018:3783-94. https:// doi.org/10.1007/s11695-018-3450-2.

15. Colquitt JL, Pickett K, Loveman E, et al. Surgery for weight loss in adults. Cochrane Database Syst Rev. 2014;8:CD003641. https:// doi.org/10.1002/14651858.CD003641.pub4.

16. NCD Risk Factor Collaboration. Trends in adult body-mass index in 200 countries from 1975 to 2014: a pooled analysis of 1698 population-based measurement studies with 19.2 million participants. Lancet. 2016;387(10026):1377-96.

17. Dindo D, Demartines N, Clavien PA. Classification of surgical complications: a new proposal with evaluation in a cohort of 6336 patients and results of a survey. Ann Surg. 2004;240:205-13.

18. Nguyen NT, Nguyen B, Gebhart A, et al. Changes in the makeup of bariatric surgery: a national increase in use of laparoscopic sleeve gastrectomy. J Am Coll Surg. 2013;216(2):252-7.
19. Welbourn R, Hollyman M, Kinsman R, et al. Bariatric surgery worldwide: baseline demographic description and one-year outcomes from the fourth IFSO global registry report 2018. Obes Surg. 2019;29:782-95.

20. Angrisani L, Santonicola A, Iovino P, et al. Bariatric surgery worldwide 2013. Obes Surg. 2015;25:1822-32.

21. Trotta M, Ferrari C, D'Alessandro G, et al. Enhanced recovery after bariatric surgery (ERABS) in a high-volume bariatric center. Surg Obes Relat Dis. 2019:1-8.

22. Bevilacqua LA., Obeid NR., Spaniolas K., Bates A., Docimo Jr. S., Pryor A. Early postoperative diet after bariatric surgery: impact on length of stay and 30-day events. Surgical Endoscopy 2018 (on line) https://doi.org/10.1007/s00464-018-6533-1

23. Wilmore DW \& Kehlet H. Management of patients in fast track surgery. BMJ 2001. v.322 24 february.

24. Dogan K, Kraaij L, Aarts EO, et al. Fast-track bariatric surgery improves perioperative care and logistics compared to conventional care. Obes Surg. 2015;25:28-35.

25. Prabhakaran S., Misra S., Magila M., Kumar S., Kasthuri S., Palanivelu C., Praveen Raj P. Randomized controlled trial comparing the outcomes of enhanced recovery after surgery and standard recovery pathways in laparoscopic sleeve gastrectomy. Obes Surg 2020. https://doi.org/10.1007/s11695-020-04585-2.

26. Ljungqvist $\mathrm{O}$, Jonathan E. Rhoads lecture 2011: insulin resistance and enhanced recovery after surgery. JPEN J Parenter Enteral Nutr. 2012;36:389-98.

27. Awad S, Varadhan KK, Ljungqvist O, et al. A metaanalysis of randomised controlled trials on preoperative oral carbohydrate treatment in elective surgery. Clin Nutr. 2013;32:34-44.

28. Smith MD, McCall J, Plank L, et al. Preoperative carbohydrate treatment for enhancing recovery after elective surgery. Cochrane Database Syst Rev. 2014;8:Cd009161.

29. Gustafsson UO, Nygren J, Thorell A, et al. Pre-operative carbohydrate loading may be used in type 2 diabetes patients. Acta Anaesthesiol Scand. 2008;52:946-51.

30. Lam J., Suzuki T., Bernstein D., Zhao B., Maeda C., Pham T., Sandler BJ., Garth R., Jacobsen GR., Cheverie JN., Horgan S. An ERAS protocol for bariatric surgery: is it safe to discharge on postoperative day 1? Surg Endosc 2018. https://doi.org/10.1007/ s00464-018-6368-9, 33, 580, 586.

31. Aktimur R, Kirkil C, Yildirim K, et al. Enhanced recovery after surgery (ERAS) in one-anastomosis gastric bypass surgery: a matched-cohort study. Surg Obes Relat Dis. 2018;14(12):1850-6. https://doi.org/10.1016/j.soard.2018.08.029.

32. Ahmed OS, Rogers AC, Bolger JC, et al. Meta-analysis of enhanced recovery protocols in bariatric surgery. J Gastrointest Surg. 2018;22:964-72.

33. IFSO - International Federation for the Surgery of Obesity and Metabolic Disorders. Fifth IFSO Global Registry Report 2019. Prepared by Almino Ramos. Lilian Kow. Wendy Brown.Richard Welbourn. John Dixon.Robin Kinsman.Peter Walton.

34. Małczak P, Pisarska M, Piotr M, et al. Enhanced recovery after bariatric surgery: systematic review and meta-analysis. Obes Surg. 2017;27:226-35.

35. Małczak $\mathrm{P}$, Wysocki $\mathrm{M}$, Twardowska $\mathrm{H}$, et al. Impact of adherence to the ERAS ${ }^{\circ}$ protocol on short-term outcomes after bariatric surgery. Obes Surg. 2020;30:1498-505. https://doi.org/10.1007/ s11695-019-04349-7.

Publisher's Note Springer Nature remains neutral with regard to jurisdictional claims in published maps and institutional affiliations. 